\title{
Isolation Enhancement of Densely Packed Array Antennas with Periodic MTM-Photonic Bandgap for SAR and MIMO Systems
}

\author{
Mohammad Alibakhshikenari ${ }^{1 *}$, Bal S. Virdee ${ }^{2}$, Panchamkumar Shukla ${ }^{2}$, Chan H. See ${ }^{3}$, \\ Raed Abd-Alhameed ${ }^{4}$, Mohsen Khalily ${ }^{5}$, Francisco Falcone ${ }^{6}$, Ernesto Limiti ${ }^{1}$ Karim Quazzane $^{2}$, Naser Parchin ${ }^{1}$ \\ ${ }^{1}$ Electronic Engineering Department, University of Rome “Tor Vergata”, Via del Politecnico 1, 00133, Rome, ITALY \\ ${ }^{2}$ London Metropolitan University, Center for Communications Technology, School of Computing \& Digital Media, London N7 8DB, UK \\ ${ }^{3}$ School of Engineering, University of Bolton, Deane Road, Bolton, BL3 5AB, UK \\ ${ }^{3}$ School of Engineering \& the Built Environment, Edinburgh Napier University, Merchiston Campus, 10 Colinton Road, Edinburgh, EH10 5DT, UK \\ ${ }^{4}$ School of Electrical Engineering \& Computer Science, University of Bradford, UK \\ ${ }^{5} 5 \mathrm{G}$ innovation Center (5GIC), Institute for Communication Systems, University of Surrey, Guildford, GU2 7XH, U.K \\ ${ }^{6}$ Electric and Electronic Engineering Department, Universidad Pública de Navarra, SPAIN \\ *alibakhshikenari@ing.uniroma2.it
}

\begin{abstract}
A metamaterial photonic bandgap (MTM-PBG) periodic structure is used as a decoupling frame to improve the isolation between transmit-receive (T/R) sections of densely packed array antenna in synthetic aperture radar (SAR) and multiple-input multiple-output (MIMO) systems. With this technique the MTM-PBG structure is shown to effectively suppress surface wave propagations between the $T / R$ array antennas by an average of $12 \mathrm{~dB}$. MTM-PBG layer comprises a periodic arrangement of dielectric circles etched in the cross-shaped microstrip frame that is inserted between the radiating elements. Unlike other recently reported methods, the advantages of the proposed technique are: (i) simplicity; (ii) cost effectiveness as there is no need for short-circuited via-holes or 3D metal walls; and (iii) can be retrofitted in existing array antennas. The proposed $T / R$ array antennas were designed to operate over an arbitrary frequency range $(9.25-11 \mathrm{GHz})$ with a fractional bandwidth (FBW) of $17.28 \%$. With this technique (i) the side-lobes are reduced; (ii) there is minimal effect on the gain performance; and (iii) the minimum edge-to-edge gap between adjacent radiating elements can be reduced to $0.15 \lambda$ at 9.25 GHz.
\end{abstract}

Index Terms-Metamaterial (MTM), photonic bandgap (PBG), periodic structures, surface wave suppression, isolation, synthetic aperture radar (SAR), multiple-input multiple-output (MIMO).

\section{INTRODUCTION}

One of the features of photonic or electromagnetic bandgap (PBG/EBG) structures is their ability to suppress surface currents within their bandgap [1]. This property can be exploited to reduce the mutual EM coupling between radiating elements resulting from surface wave currents over the antenna [2]. Although other types of techniques [3] can also be utilized for this purpose, the PBG/EBG structures offer benefits of compactness, lower integration complexity, and notable bandgap properties. PBG structures have been extensively used to improve the performances of array antennas, e.g. this can be achieved by inserting PBG structures between antenna elements in arrays to suppress mutual coupling that exists between the elements. Attributes of this technique in array antennas are: (i) gain increase [4]; (ii) better control of side-lobes [5]; and (iii) wider scan angles of phased arrays [6]. Furthermore, by reducing the mutual coupling between radiating elements enables the antennas in the array to be arranged much closer to each other. This allows for more antennas to be squeezed in the array thus increasing system capacity [7] as is evident in multiple-input-multiple-output (MIMO) wireless communication systems [8]. Application of PBG in the references cited above are focused on reduction of mutual coupling between two antenna elements. To date only a few works have been published on investigating isolation enhancement between radiating elements in a larger array antenna, which is crucial to the performance of MIMO and radar systems.

In this paper, we have shown the application of a 2dimensional MTM-PBG structure in a six-element array antenna can improve isolation between the $T / R$ radiating elements by an average of $10 \mathrm{~dB}$. MTM-PBG employed here comprised periodic arrangement of dielectric circles that essentially block propagation of surface waves within the bandgap region which is determined by the dimension of the circular slots and their spacing. The patch array antenna was designed to operate over an arbitrary frequency range of 9.25-11 GHz. MTM-PBG was realised by etching dielectric circles on microstrip-line that was inserted between the radiating elements. Results reveal the effectiveness of the MTM-PBG layer in suppressing surface wave propagations between the radiating elements, and thereby enhancing isolation between $T / R$ patches.

\section{DESIGN OF PBG STRUCTURE}

The reference X-band $\mathrm{T} / \mathrm{R}$ patch array antenna structure without MTM-PBG, shown in Fig. 1 (a) \& (b), was constructed on FR-4 lossy substrate with thickness of 1.6 $\mathrm{mm}$, dielectric constant $\left(\varepsilon_{r}\right)$ of 3.4 , and loss-tangent of 0.025 . Each of the arrays has a size of $15 \times 15 \mathrm{~mm}^{2}$ $\left(0.46 \lambda_{9.25 \mathrm{GHz}} \times 0.46 \lambda_{9.25 \mathrm{GHz}}\right)$ and consists of $3 \times 2$ microstrip patch elements. The overall antenna comprises of six square patches that are feed individually. Transmit patches are: \#1, \#3, \& \#5; and receive patches are: \#2, \#4, and \#6. The array's S-parameters response across 9.25-11 GHz are shown in Fig. 2. The average S-parameter performance is given in Table $\mathrm{I}$.

To suppress mutual coupling between the radiation elements and therefore improve $T / R$ isolation, a $2 \mathrm{D}$ periodic structure of MTM-PBG was introduced between the radiating elements, as shown in Fig. 1(c) \& (d). This consists of cross-shaped microstrip frame with periodic arrangement of circular dielectric circles etched onto the microstrip-line. MTM-PBG cross-shaped frame is $4 \mathrm{~mm}$ 
wide $\left(0.12 \lambda_{9.25 \mathrm{GHz}}\right)$. The gap between the $\mathrm{T} / \mathrm{R}$ arrays is 5 $\mathrm{mm}\left(0.15 \lambda_{9.25 \mathrm{GHz}}\right)$. Diameter of the dielectric circles and their center-to-center gap are $0.5 \mathrm{~mm}\left(0.015 \lambda_{9.25 \mathrm{GHz}}\right)$ and $1.75 \mathrm{~mm}\left(0.053 \lambda_{9.25 \mathrm{GHz}}\right)$, respectively.

TABLE I. MEASURED S-PARAMETERS For THE REFERENCE ARRAY ANTENNA WITHOUT MTM-PBG (Units are in dB)

\begin{tabular}{|c|c|c|c|c|c|c|}
\hline \multicolumn{7}{|c|}{$\mathrm{S}_{11}: 10.4-11 \mathrm{GHz}, \mathrm{FBW}=5.6 \%$} \\
\hline S-par. & $\mathrm{S}_{12}$ & $\mathrm{~S}_{13}$ & $\mathrm{~S}_{14}$ & $\mathrm{~S}_{34}$ & $\mathrm{~S}_{35}$ & $\mathrm{~S}_{36}$ \\
\hline Ave. $(\mathrm{dB})$ & -12 & -12 & -13 & -10 & -22 & -23 \\
\hline
\end{tabular}

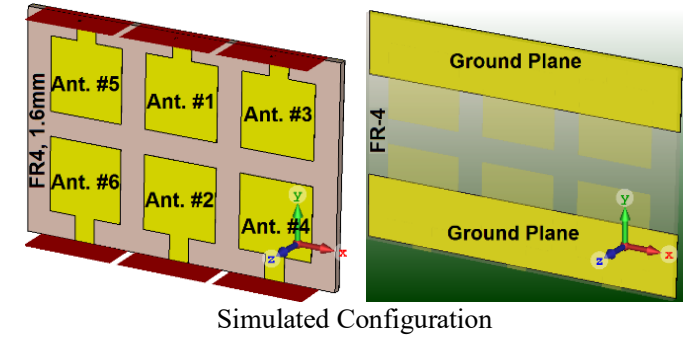

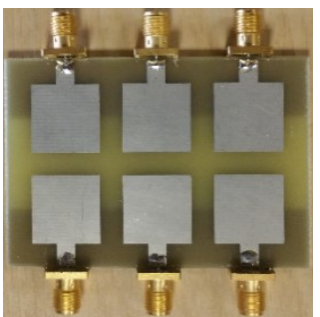

Fabricated Prototype

(a)
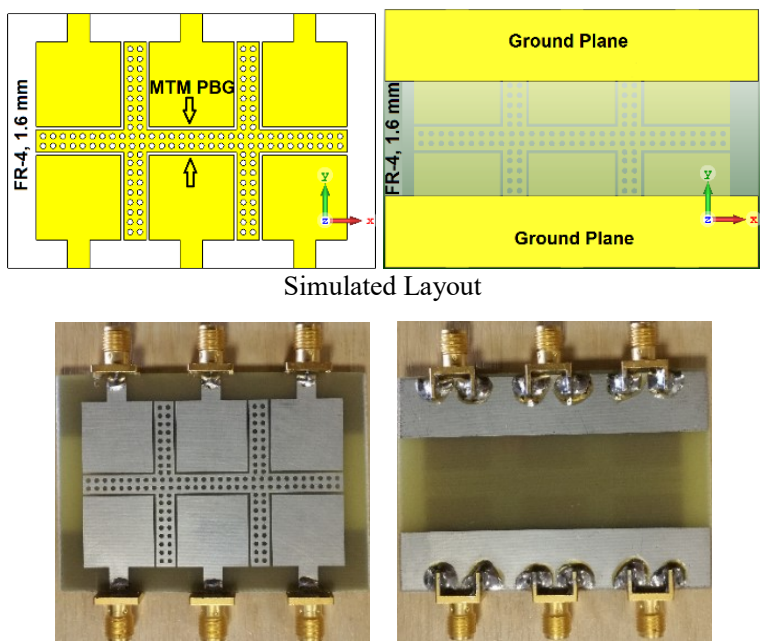

(c)
Fig. 1. Array antenna, (a)-(b) top and back views of the reference array antenna (simulation configuration and fabricated prototype); and (c)-(d) top and back views of the proposed array antenna with periodic MTMPBG (simulation configuration and fabricated prototype).

The concept of photonic bandgap was first demonstrated by authors in [9][10]. The photonic bandgap lattice structure employed here consists of circular dielectric circles embedded in the cross-shaped microstrip frame introduces series and shunt reactive elements that determine the propagation constant of the structure. Stopband condition is determined by the lattice period $a$ (i.e. gap between the dielectric circles) and filling factor $r / a$, where $r$ is the radius of the circles [11]. When this condition is satisfied, the propagation of the quasi-TEM mode is prohibited, resulting in a deep stopband.

Compared to other isolation methodologies reported in literature the proposed 2D MTM-PBG technique has advantages of: (i) relatively simple design; (ii) ease of integration and implementation inside planar array antennas; (iii) not requiring any short-circuited via-holes that can impact on manufacturing costs; and (iv) facilitates retrofitting in existing array antennas.

The S-parameter response of the MTM-PBG structure in Fig. 2(a) exhibits isolation exceeding $40 \mathrm{~dB}$ from 9.25 $\mathrm{GHz}$ to $11 \mathrm{GHz}$. S-parameter responses of the array antenna with MTM-PBG structure are shown in Fig. 2(b). The bandwidth of the array antenna of $1.75 \mathrm{GHz}$ extends between 9.25 to $11 \mathrm{GHz}$ with FBW of $17.28 \%$. The array's salient features with MTM-PBG are summarized in Table II.

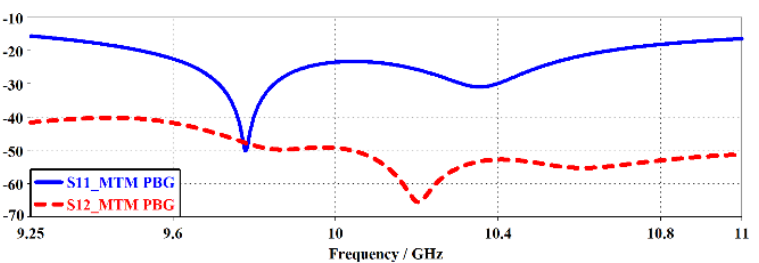

(a) S-parameter response of the MTM-PBG structure.
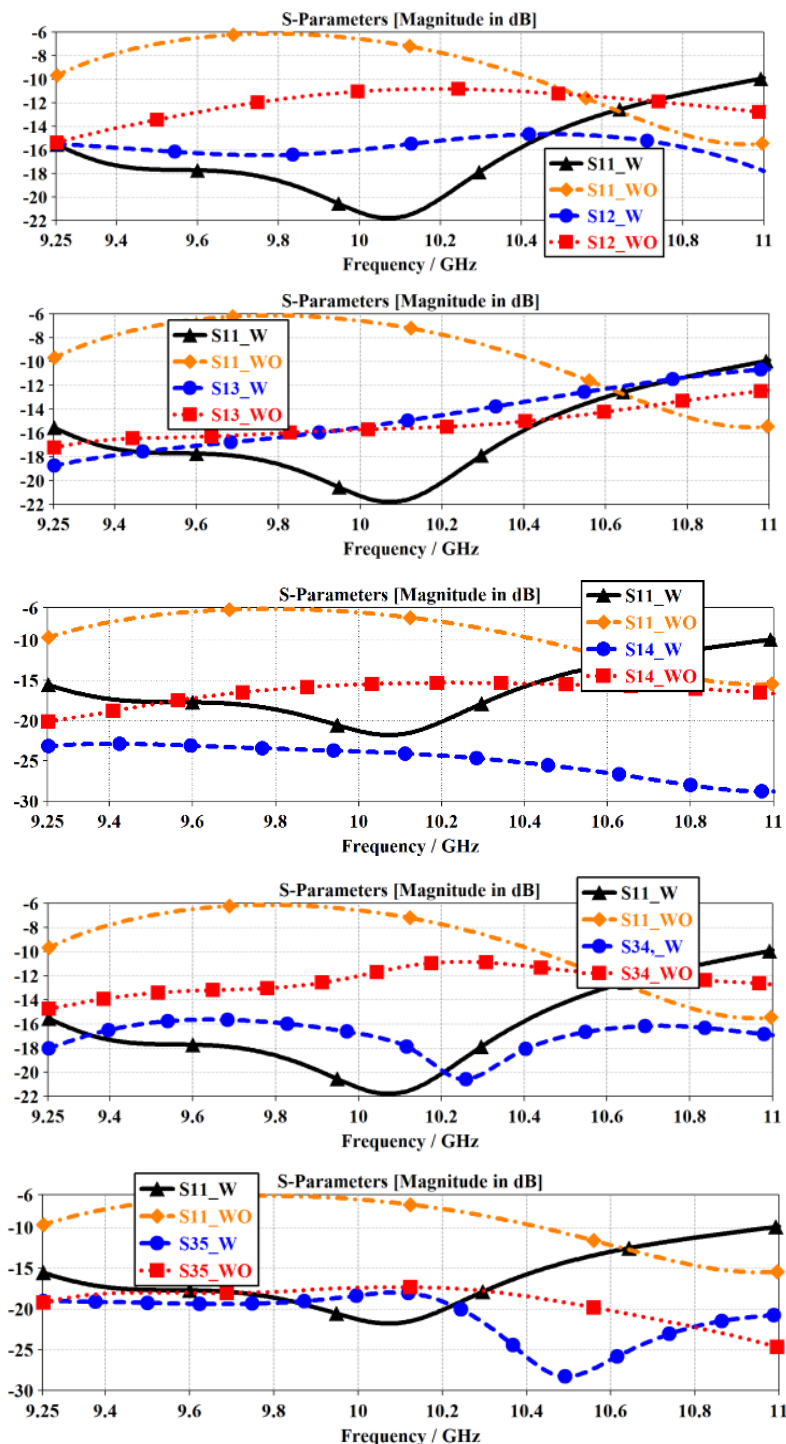


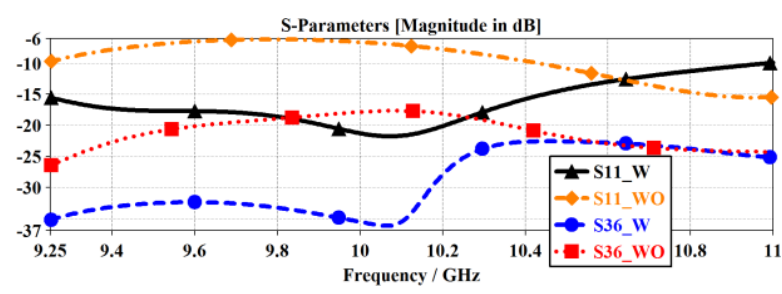

(b) S-parameter of the array antenna.

Fig. 2. Measured S-parameters of (a) the proposed MTM-PBG structure and (b) the array antenna without (WO) and with (W) MTM-PBG. As the antenna is a symmetrical configuration the following conditions apply: $\mathrm{S}_{13}=\mathrm{S}_{15}=\mathrm{S}_{24}=\mathrm{S}_{26}, \& \mathrm{~S}_{14}=\mathrm{S}_{16}=\mathrm{S}_{23}=\mathrm{S}_{25}, \& \mathrm{~S}_{34}=\mathrm{S}_{56}, \& \mathrm{~S}_{36}=\mathrm{S}_{45}, \& \mathrm{~S}_{35}=\mathrm{S}_{46}$ 'W' and 'WO' refer to 'with' and 'without' the MTM-PBG isolator, respectively.

The results in Table II demonstrate that isolation between T/R array antennas is improved by $5 \mathrm{~dB}$ (between transmit patch\#1 \& receive patch\#2), $14 \mathrm{~dB}$ (between transmit patch\#1 \& receive patch $\# 4$ ), $10 \mathrm{~dB}$ (between transmit patch $\# 3 \&$ receive patch $\# 4$ ), and $19 \mathrm{~dB}$ (between transmit patch\#3 \& receive patch\#6). There is also improvement between radiating elements in the transmit and receive sections, i.e. by $6 \mathrm{~dB}$ (between transmit patches \#1 \& \#3), and by $10 \mathrm{~dB}$ (between transmit patches \#3 \& \#5).

TABLE II. Isolation IMPRovement Using The Proposed MTM-PBG TECHNIQUE

\begin{tabular}{|c|c|c|}
\hline $\mathrm{S}_{11}$ & $\begin{array}{c}9.25-11 \mathrm{GHz}, \\
\text { FBW }=17.28 \%\end{array}$ & $\begin{array}{c}\text { Max. matching } \\
\text { improvement: } \sim 15 \mathrm{~dB}\end{array}$ \\
\hline $\mathrm{S}_{12}$ & Max. suppression: & Ave. suppression: $4 \mathrm{~dB}$ \\
$(\mathrm{~T} / \mathrm{R})$ & $5 \mathrm{~dB} @ 10.98 \mathrm{GHz}$ & \\
\hline $\mathrm{S}_{13}$ & Max. suppression: & Ave. suppression: $3 \mathrm{~dB}$ \\
$(\mathrm{~T} / \mathrm{T})$ & $6 \mathrm{~dB} @ 9.25 \mathrm{GHz}$ & \\
\hline $\mathrm{S}_{14}$ & Max. suppression: & Ave. suppression: $10 \mathrm{~dB}$ \\
$(\mathrm{~T} / \mathrm{R})$ & $14 \mathrm{~dB} @ 10.97 \mathrm{GHz}$ & \\
\hline $\mathrm{S}_{34}$ & Max. suppression: & Ave. suppression: $8 \mathrm{~dB}$ \\
$(\mathrm{~T} / \mathrm{R})$ & $10 \mathrm{~dB} @ 10.25 \mathrm{GHz}$ & \\
\hline $\mathrm{S}_{35}$ & Max. suppression: & Ave. suppression: $5 \mathrm{~dB}$ \\
$(\mathrm{~T} / \mathrm{T})$ & $10 \mathrm{~dB} @ 10.5 \mathrm{GHz}$ & \\
\hline $\mathrm{S}_{36}$ & Max. suppression: & Ave. suppression: $7 \mathrm{~dB}$ \\
$(\mathrm{~T} / \mathrm{R})$ & $19 \mathrm{~dB} @ 10.07 \mathrm{GHz}$ & \\
\hline
\end{tabular}

The simplified equivalent electrical circuit model of the $3 \times 2$ array antenna with MTM-PBG structure is shown in Fig. 3, where the patches and MTM-PBG are represented as parallel $R L C$ circuit. The patch radiator is represented by a resonant circuit comprising inductance $\left(L_{P}\right)$, capacitance $\left(C_{P}\right)$, and resistance $\left(R_{P}\right)$ accounting for the Ohmic and dielectric loss. Similarly, MTM-PBG is represented with inductance $\left(L_{D S}\right)$, capacitance $\left(C_{D S}\right)$, and resistance $\left(R_{D S}\right)$. Coupling between the patches and MTM-PBG are represented by $K_{D S}$. The optimised values of the equivalent circuit model were extracted using optimization tool in full-wave EM simulation by CST at $10 \mathrm{GHz}$. Magnitudes of these parameters are given in Table III.

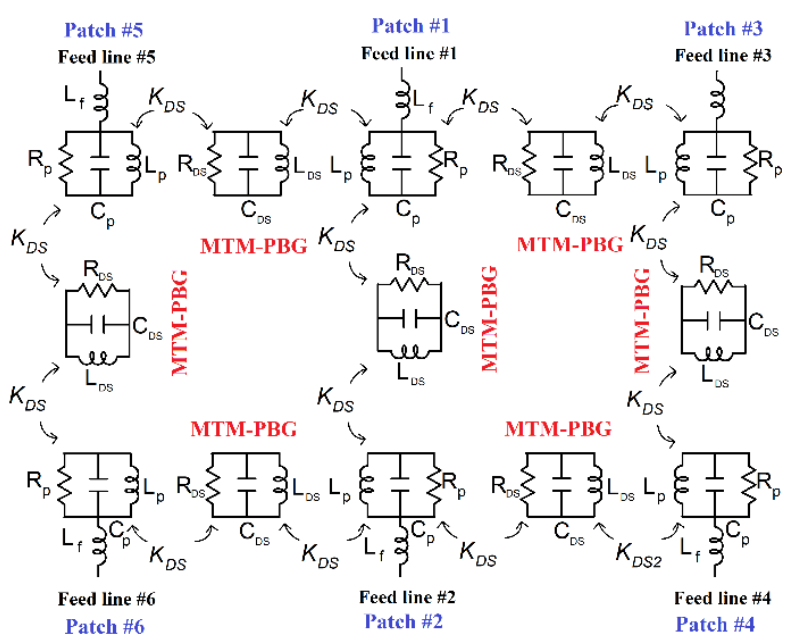

Fig. 3. Simplified equivalent electrical circuit model of the proposed $3 \times 2$ array antennas loaded with MTM-PBG decoupling slab.

Input impedance of the proposed array antenna computed using CST Microwave studio and equivalent electrical circuit model are shown in Fig. 4. There is excellent correlation in input impedance response between the circuit model and CST Microwave Studio. This is because the equivalent circuit model parameters were extracted using optimization method in full-wave EM simulation CST over the specified frequency range.

TABLE III

EXTRACTED PARAMETERS OF THE EQUIVALENT CIRCUIT MODEL OF FIG.3 AT $10 \mathrm{GHz}$

\begin{tabular}{|c|c|}
\hline Extracted Parameters & Value \\
\hline$C_{P}$ & $0.97 \mathrm{pF}$ \\
\hline$L_{P}$ & $0.26 \mathrm{nH}$ \\
\hline$R_{P}$ & $55 \Omega$ \\
\hline$C_{D S}$ & $2.15 \mathrm{pF}$ \\
\hline$L_{D S}$ & $0.12 \mathrm{nH}$ \\
\hline$R_{D S}$ & $2200 \Omega$ \\
\hline$K_{D S}$ & 0.0098 \\
\hline$L_{f}$ & $2.4 \mathrm{nH}$ \\
\hline
\end{tabular}

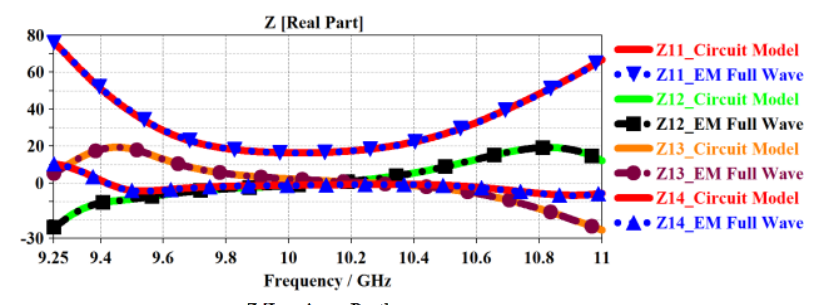
$\mathrm{Z}$ [Imaginary Part]

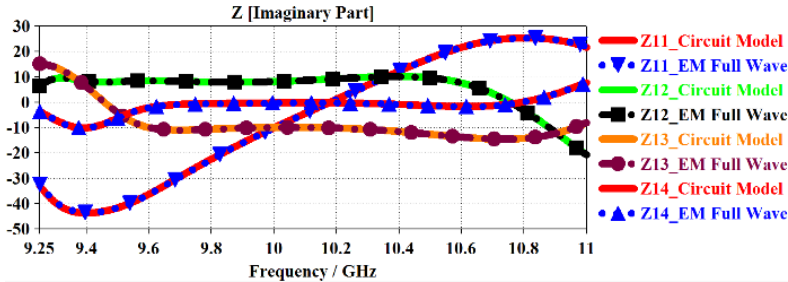




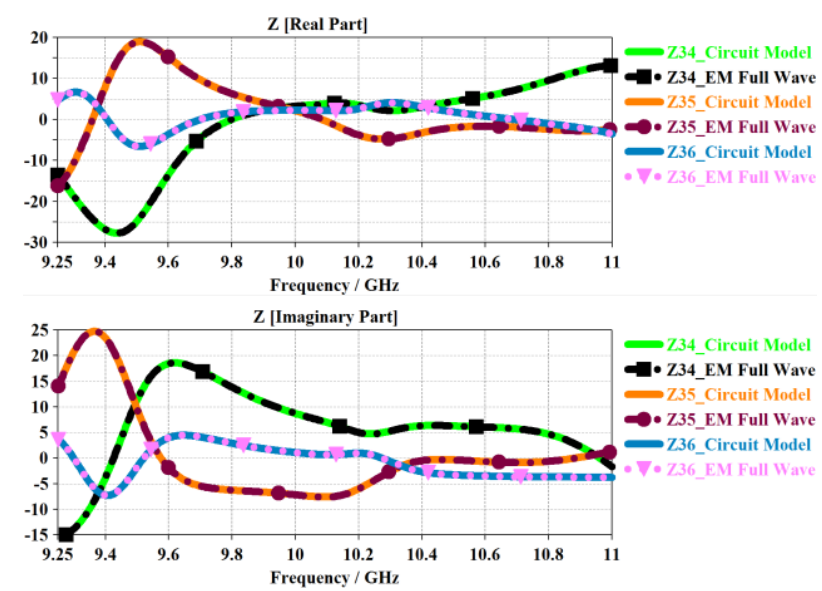

Fig. 4. Input impedances (unit is in $\Omega$ ) of the proposed array antennas loaded by the periodic MTM-PBG.

Surface current distribution 'with' and 'with no' MTMPBG isolator, shown in Fig. 5, provides further insight how the surface currents are suppressed. It is evident the crossshaped MTM-PBG decoupling slab significantly interacts with the surface currents to block them from affecting adjacent radiation elements in the array antenna. Destructive effects of surface currents in the antenna are significantly suppressed from effecting the far-field of the antenna array.

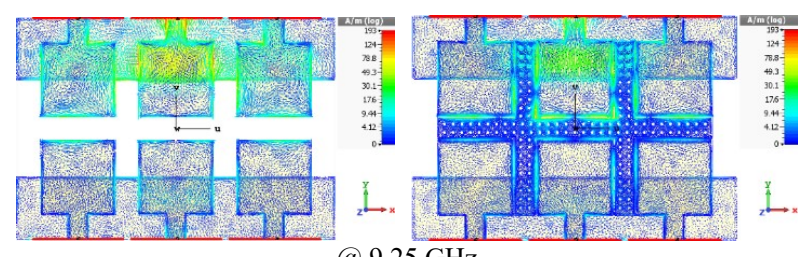

(a) $9.25 \overline{\mathrm{GHz}}$

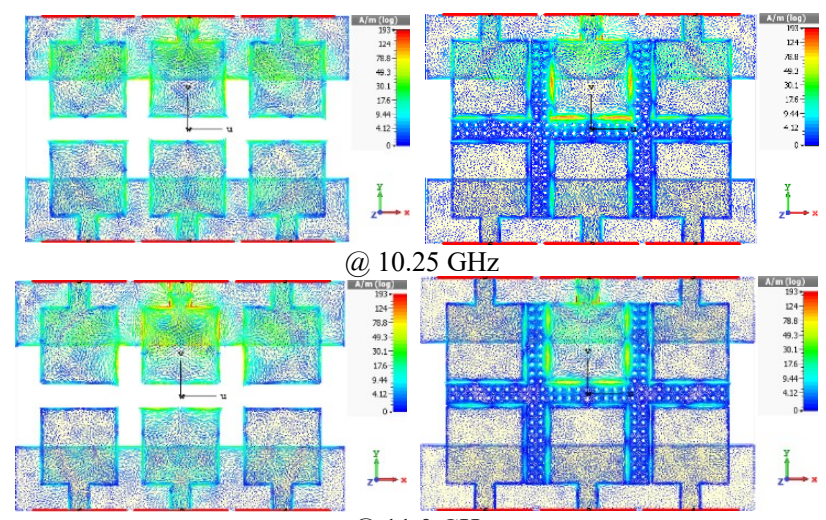

(a) $11.0 \mathrm{GHz}$

Fig. 5. Surface current density distributions over the array antennas without (left side) and with (right side) MTM PBG at working frequencies. It is worth to comment that here to save space, we have only shown the surface current distributions stimulated by port \#1.

Radiation performance of the array antennas was measured in a standard anechoic chamber where the antenna under test (AUT) was mounted on a rotating stand across from a reference antenna. This test setup was used to measure the transmission coefficient $\left(\mathrm{S}_{21}\right)$ by exciting the reference antenna and then measuring the power received by the AUT. The AUT is rotated $360^{\circ}$. The reference antenna is a broadband horn. Measurements were conducted at four spot frequencies and the results are plotted in normalized dB. Fig. 6 shows the measured radiation patterns of the array antenna 'with' (W) and 'without' (WO) MTM-PBG structure at the operational frequency. MTM-PBG structure which is disposed between the patches eliminates propagation of surface waves on the substrate which would otherwise undermine the antenna performance. MTM-PBG structure improves isolation between the patches in the array however it doesn't affect the far-field radiation because the EM-fields that contribute to far-field radiation are orthogonal to the surface of the antenna plane. This is verified in the measured far-field radiation patterns. Compared to the reference antenna array, the array with the MTM-PBG structure exhibits improved radiation characteristics in terms of side-lobe suppression and there is negligible effect on the gain performance.
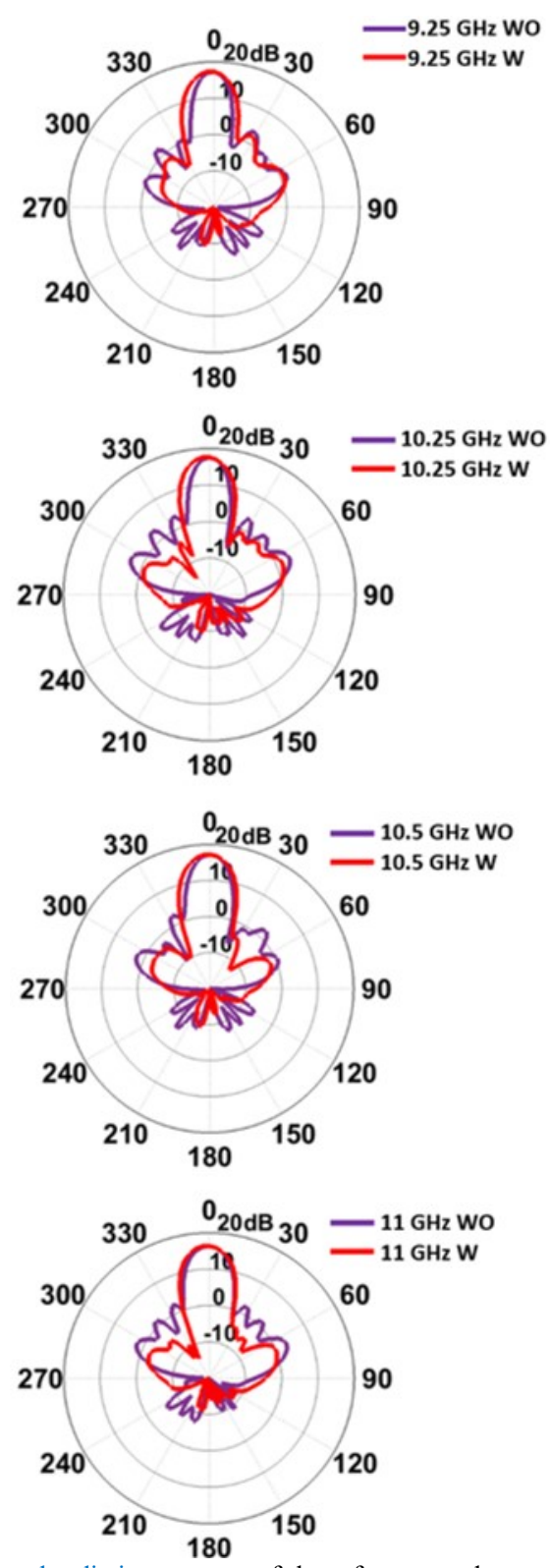

Fig. 6. Measured radiation patterns of the reference and proposed array antennas without (WO) and with (W) MTM-PBG isolator at the specified spot frequencies. 
The simulated and measured radiation gain and efficiency plots of the proposed array antennas 'without' and 'with' MTM-PBG isolator are shown in Fig. 7. There is good correlation between the simulation and measured graphs. The optimum measured gain and efficiency of the array antenna loaded with MTM-PBG are $7.85 \mathrm{dBi}$ and $92.78 \%$, respectively, at $10.6 \mathrm{GHz}$. Without MTM-PBG the optimum gain and efficiency are $7.38 \mathrm{dBi}$ and $88.05 \%$, respectively, at $10.6 \mathrm{GHz}$. These results show that the radiation performance is not severely affected by applying MTM-PBG isolator.

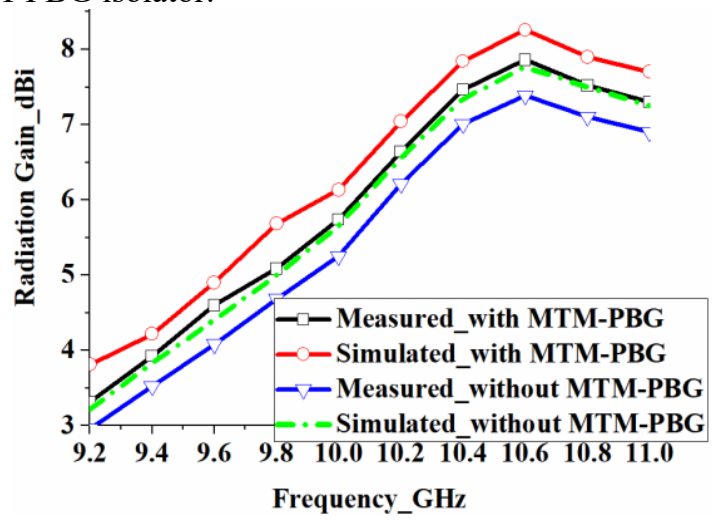

(a) Radiation gain

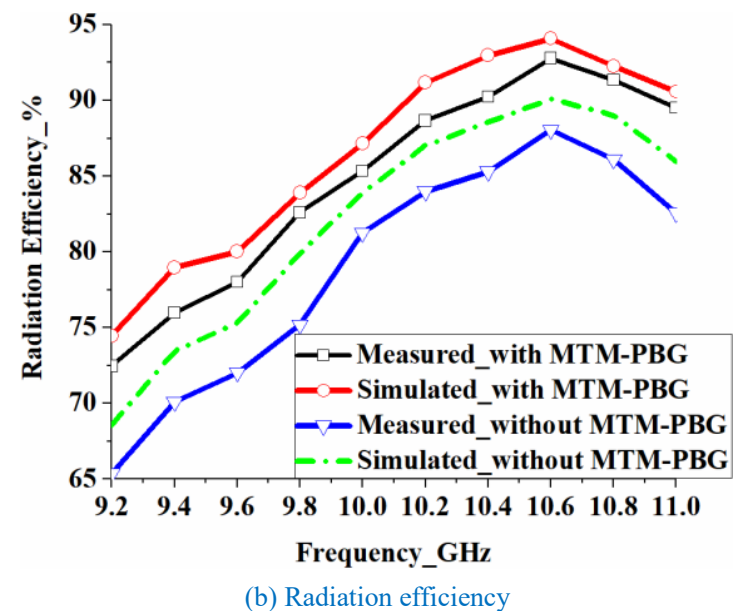

Fig. 7. Simulated and measured radiation gain and efficiency of the proposed array antennas 'without' and 'with' MTM-PBG isolator over its operating frequency range.
Performance of the proposed technique is compared with other antenna isolation mechanisms reported in literature in Table IV. In the literature all the antenna designs were constructed using two radiation elements. However, in our case here we have used array elements of six to give a more accurate representation. In addition, all the references cited in Table IV except for [30]-[36] have used the defected ground structure (DGS) technique to enhance isolation between the two radiating elements. It is also evident from the table that antenna arrays with smaller edge-to-edge gap between adjacent radiating elements operate over a narrow bandwidth and their radiation patterns are degraded, whereas the proposed array antenna operates a wider bandwidth and its radiation patterns are improved. The proposed method described here offers an optimum T/R isolation of $10 \mathrm{~dB}$. Although references such as [27][28] provide better isolation by employing shortcircuit vias however they have a narrow bandwidth. In general, compared to other techniques cited in Table III the proposed approach provides simultaneously high isolation, wider bandwidth, minimal effect on radiation pattern, and with no ground-plane defection. In addition, the proposed technique offers design simplicity and it can be easily retrofitted to existing antenna arrays quickly and at low cost.

\section{CONCLUSIONS}

A simple and effective mutual coupling reduction technique is demonstrated using MTM-PBG cross-shaped frame that is located between the radiating transmit/receive array antennas. The MTM-PBG structure is a microstrip frame with periodically arranged dielectric circles. This structure blocks propagation of surface waves on the arrays antennas to improve isolation between the transmit/receive array antennas. Average isolation between the transmit/receive array antennas is improved by $12 \mathrm{~dB}$. This $2 \mathrm{D}$ technique is simple to implement in practice and offers the advantage of retrofitting on existing array antennas. This structure should be suitable for the SAR and MIMO systems that require high $\mathrm{T} / \mathrm{R}$ isolations. 
TABLE IV. Comparison Between The Proposed ArRay With The Recent Works

\begin{tabular}{|c|c|c|c|c|c|c|c|}
\hline Ref. & Method & Max. isolation & $\begin{array}{c}\text { Fractional } \\
\text { Bandwidth } \\
\text { (FBW) }\end{array}$ & $\begin{array}{c}\text { Rad. pattern } \\
\text { adversely } \\
\text { affected }\end{array}$ & $\begin{array}{l}\text { Number of } \\
\text { elements }\end{array}$ & $\begin{array}{c}\text { Applied } \\
\text { DGS } \\
\text { Technique }\end{array}$ & $\begin{array}{l}\text { Edge-to-Edge Gap } \\
\text { Between Adjacent } \\
\text { Radiating Elements }\end{array}$ \\
\hline [3] & EBG & $8.8 \mathrm{~dB}$ & Narrow & - & 2 & Yes & $0.75 \lambda_{0}$ \\
\hline [12] & $\begin{array}{c}\text { Defected Ground } \\
\text { Structure }\end{array}$ & $17.4 \mathrm{~dB}$ & Narrow & Yes & 2 & Yes & $0.23 \lambda_{0}$ \\
\hline [13] & SCSRR & $10 \mathrm{~dB}$ & Narrow & Yes & 2 & Yes & $0.25 \lambda_{0}$ \\
\hline [14] & SCSSRR & $14.6 \mathrm{~dB}$ & Narrow & Yes & 2 & Yes & $0.125 \lambda_{0}$ \\
\hline$[15]$ & Compact EBG & $17 \mathrm{~dB}$ & Narrow & Yes & 2 & Yes & $0.8 \lambda_{0}$ \\
\hline [16] & U-Shaped Resonator & $10 \mathrm{~dB}$ & Narrow & Yes & 2 & Yes & $0.6 \lambda_{0}$ \\
\hline [17] & Meander Line Resonator & $10 \mathrm{~dB}$ & Narrow & No & 2 & Yes & $0.055 \lambda_{0}$ \\
\hline [18] & UC-EBG & $14 \mathrm{~dB}$ & Narrow & Yes & 2 & Yes & $0.5 \lambda_{0}$ \\
\hline [19] & EBG & $10 \mathrm{~dB}$ & Narrow & Yes & 2 & Yes & $0.5 \lambda_{0}$ \\
\hline [20] & EBG & $5 \mathrm{~dB}$ & Wide $(\sim 16 \%)$ & - & 2 & Yes & $0.6 \lambda_{0}$ \\
\hline [21] & EBG & $13 \mathrm{~dB}$ & Wide $(\sim 12 \%)$ & Yes & 2 & Yes & $0.5 \lambda_{0}$ \\
\hline [22] & EBG\&DGS & $16 \mathrm{~dB}$ & Narrow & No & 2 & Yes & $0.6 \lambda_{0}$ \\
\hline [23] & Fractal load with DGS & $16 \mathrm{~dB}$ & Narrow $(2.5 \%)$ & No & 2 & Yes & $0.22 \lambda_{0}$ \\
\hline [24] & EBG & $4 \mathrm{~dB}$ & Narrow & Yes & 2 & Yes & $0.84 \lambda_{0}$ \\
\hline$[25]$ & $\begin{array}{l}\text { Slotted Meander-Line } \\
\text { Resonator }\end{array}$ & $16 \mathrm{~dB}$ & Narrow & Yes & 2 & Yes & $0.11 \lambda_{0}$ \\
\hline [26] & I-Shaped Resonator & $30 \mathrm{~dB}$ & Narrow & Yes & 2 & Yes & $0.45 \lambda_{0}$ \\
\hline [27] & $\mathrm{W} / \mathrm{g}$ MTM & $20 \mathrm{~dB}$ & Narrow & No & 2 & Yes & $0.125 \lambda_{0}$ \\
\hline [28] & W/g MTM & $18 \mathrm{~dB}$ & Narrow & No & 2 & Yes & $0.093 \lambda_{0}$ \\
\hline [29] & UC-EBG & $10 \mathrm{~dB}$ & Narrow & Yes & 2 & Yes & $0.5 \lambda_{0}$ \\
\hline$[30]$ & Coupled Resonator & $10 \mathrm{~dB}$ & Wide $(15 \%)$ & Yes & 2 & No & $0.15 \lambda_{0}$ \\
\hline$[31]$ & Coupled Resonator & $20 \mathrm{~dB}$ & Narrow & - & 2 & No & - \\
\hline$[32]$ & $\begin{array}{l}\text { Reactively Loaded } \\
\text { Dummy Elements }\end{array}$ & $20 \mathrm{~dB}$ & Narrow & - & 4 & No & $0.21 \lambda_{0}$ \\
\hline [33] & Interference Cancellation & $15 \mathrm{~dB}$ & Narrow & - & 2 & No & - \\
\hline [34] & MTM & 18 & Narrow & No & 2 & No & $0.13 \lambda_{0}$ \\
\hline [35] & Multi-Layered EBG & 30 & Narrow & Yes & 2 & No & $0.13 \lambda_{0}$ \\
\hline [36] & $\begin{array}{c}\text { Dual-Band Coupled } \\
\text { Resonator }\end{array}$ & 15 & Narrow & Yes & 2 & No & $0.13 \lambda_{0}$ \\
\hline $\begin{array}{l}\text { This } \\
\text { work }\end{array}$ & MTM-PBG & $10 \mathrm{~dB}$ & $\begin{array}{l}\text { Wide } \\
(\sim 17 \%)\end{array}$ & No & 6 & NO & $0.15 \lambda_{0}$ \\
\hline
\end{tabular}

\section{ACKNOWLEDGMENT}

This work is partially supported by innovation programme under grant agreement H2020-MSCA-ITN-2016 SECRET-722424 and the financial support from the UK Engineering and Physical Sciences Research Council (EPSRC) under grant EP/E022936/1.

\section{REFERENCES}

[1] D. Sievenpiper, L. Zhang, R. F. J. Broas, N. G. Aleóxpolous, and E. Yablonovitch, "High-impedance electromagnetic surfaces with a forbidden frequency band," IEEE Trans. Microw. Theory Tech., vol. 47, no. 11, pp. 2059-2074, Nov. 1999.

[2] M. Alibakhshikenari, M. Vittori, S. Colangeli, B. S. Virdee, A. Andújar, J. Anguera, and E. Limiti, "EM isolation enhancement based on metamaterial concept in antenna array system to support full-duplex application," IEEE Asia Pacific Microwave Conf. pp. 740-742, 13-16 Nov. 2017.

[3] F. Yang, Y. Rahmat-Samii, "Microstrip antennas integrated with electromagnetic band-gap (EBG) structures: A low mutual coupling design for array applications," IEEE Trans. Antennas Propag., vol. 51, no. 10, pp. 2936-2946, Oct. 2003.

[4] P.-S. Kildal, "Artificially soft and hard surfaces in electromagnetics," IEEE Trans. Antennas Propag., vol. 38, no. 10, pp.1537-1544, Oct. 1990.

[5] L. Li, X. J. Dang, B. Li, and C. H. Liang, “Analysis and design of waveguide slot antenna array integrated with electromagnetic band-gap structures," IEEE Ant. Wireless Progag. Lett., vol. 5, pp. 111-115, 2006.

[6] Z. Iluz, R. Shavit, and R. Bauer, "Microstrip antenna phased array with electromagnetic bandgap substrate," IEEE Trans. Antennas Propag., vol. 52, no. 6, pp. 1446-1453, Jun. 2004.

[7] M. Coulombe, S. F. Koodiani, C. Caloz, "Compact elongated mushroom (EM)-EBG structure for enhancement of patch antenna array performances," IEEE Tr. Ant. Propag., vol. 58, pp.1076-1086, Apr. 2010.

[8] E. Michailidis, C. Tsimenidis, and G. Chester, "Mutual coupling reduction in a linear two element patch array and its effect on theoretical MIMO capacity," Proc. Loughborough Ant. Propag. Conf., pp. 457-460, 2008.

[9] Q. Xue, K.M. Sham, and C.H. Chan, "Novel 1-D microstrip PBG cells," IEEE Microwave Guided Wave Lett., vol. 10, pp. 403-405, 2000. 
[10] Y. Qian, V. Radisic, and T. Itoh, "Simulation and experiment of photonic bandgap structures for microstrip circuits," IEEE APMC. Symp. Dig., Hong Kong, Dec. 2-5, pp. 585-588, 1997.

[11] M. M. Karbassian, H.Ghafouri-Shiraz, "effect of shape of patterns on the performance of microstrip photonic band-gap filters," Microwave \& Optical Tech. Lett., vol. 48, no. 6, pp. 10071011, June 2006.

[12] J. OuYang, F. Yang, and Z. M. Wang, "Reduction of mutual coupling of closely spaced microstrip MIMO antennas for WLAN application," IEEE Ant. Wireless Propa. Letters, vol. 10, pp. 310-312, 2011.

[13] F. G. Zhu, J. D. Xu, and Q. Xu, "Reduction of mutual coupling between closely packed antenna elements using defected ground structure," Electronics Letters, vol. 45, no. 12, pp. 601-602, 2012.

[14] M. M. B. Suwailam, O. F. Siddiqui, and O. M. Ramahi, "Mutual coupling reduction between microstrip patch antennas using slotted-complementary split-ring resonators," IEEE Antennas \& Wireless Propag., Lett., vol. 9, pp. 876-878, 2010.

[15] M. F. Shafique, Z. Qamar, L. Riaz, R. Saleem, and S. A. Khan, "Coupling suppression in densely packed microstrip arrays using metamaterial structure," Microwave and Optical Technology Letters, vol. 57, No. 3, pp. 759-763, 2015.

[16] M. T. Islam, and M. S. Alam, "Compact EBG structure for alleviating mutual coupling between patch antenna array elements," Progress in Electromagnetics Research, vol. 137, pp. 425-38, 2013.

[17] S. Farsi, D. Schreurs, and B. Nauwelaers, "Mutual coupling reduction of planar antenna by using a simple microstrip usection," IEEE Antennas \& Wireless Propag. Letters, vol. 11, pp. 1501-1503, 2012

[18] J. Ghosh, S. Ghosal, D. Mitra, and S. R. B. Chaudhuri, "Mutual coupling reduction between closely placed microstrip patch antenna using meander line resonator," Progress in Electromagnetic Research Letters, vol. 59, pp. 115-122, 2016.

[19] H. S. Farahani, M. Veysi, M. Kamyab, and A. Tadjalli, "Mutual coupling reduction in patch antenna arrays using a UCEBG superstrate," IEEE Antennas \& Wireless Prop. Lett., vol. 9, pp. 57-59, 2010.

[20] G. Exposito-Dominguez, J. M. Fernandez-Gonzalez, P. Padilla, and M. Sierra-Castaner, "New EBG solutions for mutual coupling reduction," Eur. Conf. Antennas Propag., Prague, Czech Republic, pp. 2841-2844, 2012.

[21] M. J. Al-Hasan, T. A. Denidni, and A. R. Sebak, "Millimeter wave compact EBG structure for mutual coupling reduction applications," IEEE Trans. Antennas Propag., vol. 63, no. 2, pp. 823-828, Feb. 2015.

[22] G. Exposito-Dominguez, J. M. Fernandez-Gonzalez, P. Padilla, and M. Sierra-Castaner, "Mutual coupling reduction using EBG in steering antennas," IEEE Antennas \& Wireless Propag. Lett., vol. 11, pp. 1265-1268, 2012.

[23] X. Yang, Y. Liu, Y.-X. Xu, and S.-X. Gong, "Isolation enhancement in patch antenna array with fractal UC-EBG structure and cross slot", IEEE Antennas \& Wireless Propag. Lett., vol. 16, pp. 2175-2178, 2017.

[24] A. Yu, and X. Zhang, "A novel method to improve the performance of microstrip antenna arrays using a dumbbell EBG structure," IEEE Antennas \& Wireless Propag. Letters, vol. 2, No. 1, pp. 170-172, 2003.

[25] M. G. Alsath, M. Kanagasabai, and B. Balasubramanian, "Implementation of slotted meander line resonators for isolation enhancement in microstrip patch antenna arrays," IEEE Antennas and Wireless Propag. Letters, vol. 12, pp. 15-18, 2013.

[26] C. K. Ghosh, and S. K. Parui, "Reduction of mutual coupling between E-shaped microstrip antennas by using a simple microstrip I-section," Microwave \& Optical Tech. Lett., vol. 55, no. 11, pp. 2544-2549, 2013.

[27] X. M. Yang, X. G. Liu, X. Y. Zhu, and T. J. Cui, "Reduction of mutual coupling between closely packed patch antenna using waveguide metamaterials," IEEE Antennas \& Wireless Propag. Lett., vol. 11, pp. 389-391, 2012.

[28] Z. Qamar, and H. C. Park, "Compact waveguided metamaterials for suppression of mutual coupling in microstrip array," Progress in Electromagnetic Research, vol. 149, pp. 183192,2014

[29] H. S. Farahani, M. Veysi, M. Kamyab, and A. Tadjalli, "Mutual coupling reduction in patch antenna arrays using a UCEBG superstate," IEEE Antennas Wireless Propagation Letters, vol. 9, pp.57-59, 2010.

[30] L. Zhao, L. P. Yeung, K.-L. Wu, "A coupled resonator decoupling network for two-element compact antenna arrays in mobile terminals," IEEE Tran Ant. \& Propag., vol. 62, pp. 27672776, 2014.

[31] L. Zhao, K.-W. Qian, K.-L. Wu, "A cascaded coupled resonator decoupling network for mitigating interference between two radios in adjacent frequency bands," IEEE Trans. on Microwave Theory \& Tech., vol. 62, pp. 2680-2688, 2014.

[32] L. Zhao, K.-L. Wu, "A decoupling technique for fourelement symmetric arrays with reactively loaded dummy elements," IEEE Transactions on Ant. \& Propagation, vol. 62, pp. 4416-4421, 2014.

[33] L. Zhao, F. Liu, X. Shen, G. Jing, Y. Cai and Y. Li, "A highpass antenna interference cancellation chip for mutual coupling reduction of antennas in contiguous frequency bands," IEEE Access, vol. 6, pp. 38097- 38105, 2018.

[34] K. Yu, Y. Li, X. Liu, "Mutual coupling reduction of a MIMO antenna array using 3-D novel meta-material structures," Applied Computational Electromagnetics Society Journal, vol.33, no.7, pp.758-763, 2018 .

[35] T. Jiang, T. Jiao, Y. Li, W. Yu, "A low mutual coupling MIMO antenna using periodic multi-layered electromagnetic band gap structures," Applied Computational Electromagnetics Society Journal, vol.33, no.3, pp. 305-311, 2018.

[36] L. Zhao, K.-L. Wu, "A dual-band coupled resonator decoupling network for two coupled antennas," IEEE Trans. on Antennas and Propagation, vol. 63, pp. 2843-2850, 2015. 